\title{
That's entertainment: crafting a creative ecology within public television
}

Grant Mooney, University of Technology Sydney, Australia, grant.mooney@uts.edu.au (corresponding author)

Stephen Burdon, University of Technology Sydney, Australia, stephen.burdon@uts.edu.au Kyeong Kang, University of Technology Sydney, Australia, kyeong.kang@uts.edu.au

\begin{abstract}
Television has gone through a period of rapid disruption in the last few years. New technologies, increased globalization, shifting demographics and evolving consumer demand have impelled widespread change to business models. Consequently, Broadcasters have been forced to re-examine their approaches to creativity and ideation including capacities and enabling methods. Following analysis of recorded interviews with key personnel behind three recent television productions a clearer understanding the cultural ecology of creativity and dependencies was developed. Findings emphasised the decisive influence that internal sense of community, tacit realisation practices and quality leadership - all working together - play in delivering a distinctive production to a mass-market media audience.
\end{abstract}

\section{Introduction}

Ability to creatively innovate has been repeatedly identified as a cornerstone of successful organisations. However, only about $7 \%$ of senior executives are able to articulate the value proposition at stake (Gottlieb \& Willmott, 2014).

This is particularly germane to a television sector where nowadays three characteristics appear prevalent: first, is the need for agility in a market where change is a constant feature (Doyle, 2010); second, is the transition to digital technologies providing an expanded reach where content of all kinds can be delivered to an even wider demographic and across more platforms than at any earlier time; third is that programming appeal requires a level of distinctiveness. 
Additionally, Hesmondhalgh \& Baker (2008) point out that media industries stand as primary disseminators not only of content but of culture for modern societies. This suggests that media organisations, and especially television, have a compelling capability to influence societal paradigms if they can find novel ways to capture audience interest.

Australia is a case in point. Historically, the Australian broadcast media landscape has been dominated by three main commercial channels in each state (with a few regional affiliates) plus the Australian Broadcasting Corporation (ABC) nationwide. The small number of television channels allowed the ABC a major influence over how Australia viewed itself. Government financed and with national reach the $\mathrm{ABC}$ automatically had opportunity to shape perspectives via its public service mandate - media rivalry wasn't a strong focus. However, in the wake of post-2000 technical advances this is no longer the case. Inasmuch as 'TV production teams have their success measured, at least partly, by how different one product is from those that have gone before' (Carter \& West, 1998, p.586) the public broadcaster has been challenged to reinvent itself for a younger, much more technologically literate and informed generation of consumers - and one not satisfied with their parent's more traditional worldview. For the first time in its long history the $\mathrm{ABC}$ has had to seriously compete for its audience.

This research explores behaviours for building creative appeal within television productions at the Australian Broadcasting Corporation. Via discussions with management and creatives behind three nationally televised series, the authors aimed to better understand two concepts:

1. Attributes fostering creativity in broadcast programming;

2. Ecological approaches required to promote program distinctiveness.

Examining production teams at their craft it was hoped to better frame decision-making, priorities and behaviours behind their creative work. The paper initially presents an overview of literature with particular reference to the Australian media context, a description of the research methodology and findings/discussion. Finally, conclusions are summarised. 


\section{Literature review}

Historically, much of television programming is heavily derivative not innovative. Programs looked similar from country to country; news and current affairs programs adopt comparable presentation styles; dramas focus upon crime and punishment; soap-operas and sit-coms recycle narratives (Keane \& Moran, 2008). Magder (2004, p.143), commenting on the preGFC media industry, stated that 'the day to day business of TV runs on habit' with little room for human ingenuity. However, that was then and this is now. Evolutions in technology, franchising, globalisation, demographics and consumer demand have forced television (especially public television) to deeply reexamine relevance in a world where the need for greater adaptability directly conflicts with long-standing management canon.

This is particularly relevant to Australian media. Referring to the television climate of the late $20^{\text {th }}$ century, O'Regan \& Potter $(2013$, p.7) attest that Australia mainly developed programming for local consumption: 'Australian producers were once almost exclusively Australian companies accessing Australian funding schemes and courting international partners. They produced programs to imported and locally developed formats and created...television drama'. International recognition was garnered by presenting formulaic offerings within a novelty setting, as Australia was often regarded (e.g. Skippy the Bush Kangaroo can be seen as a reworking of Lassie, Flipper, My Friend Flicka and so on).

Prior to the new millennium, the local market was relatively limited: a few commercial freeto-air outlets such as channels seven, nine and ten (also replicating content to regional affiliate stations); a small number of specialist subscription-pay stations (e.g. Galaxy, OptusVision, Foxtel, Northgate, Austar, SelecTV, Showtime, etc.) some of which are now defunct; and two major public broadcasters, the ABC plus niche-provider SBS. Structures enabling this market were reliable and well-proven with production houses staying within specific genres (e.g. Crawford Productions targeting police/law and period drama series, Reg Grundy Productions 
for game shows and soap operas, etc.). The prevailing mode of thought for the Australian television industry at this time was one of stability, efficiency and cost-containment. This was articulated by Brian Johns, Managing Director of the ABC (1995-2000), who announced in 1996 that the main objective of internal reform for the broadcaster was not creative regeneration but an outcome that 'allows us to better control our production costs' (Dunne 2007, p.4). In the two years following, the $A B C$ reduced funds for in-house television production by $25 \%$ preferring to instead schedule dramas and comedy sourced from the United Kingdom's BBC.

Then came disruption. Like elsewhere in the post-millennium landscape, globalising processes rapidly reached down into programming practices and multinational producers entered the Australian market with a vengeance. Free-to-air networks and digital side channels contested with global TV network brands in pay TV and an increasing number of online providers. Smartphones/tablets and technology convergence (e.g. radio, television and print media available on a single device) expanded competition for limited media advertising budget across non-traditional platforms. Coordinated operations of aggressively expansionist transnationals increasingly shaped of local production and screen policy (O'Regan \& Potter 2013) seeking to outmaneuver media guidelines governing development of local content in favour of accommodating parent company formats and program orientations.

Coupling wider perspectives to high-impact original programming became a way for local producers to stand out among the sudden plethora of international competitors. Hesmondhalgh \& Baker (2011) specifically note the television industry as a sector where ongoing success necessitates a continuous flow of new ideas; going even further, Doyle \& Paterson (2008) identify that a production environment conducive to creativity and entrepreneurialism is necessary bedrock for a healthy and vibrant indigenous television economy to flourish. 
Such research also suggests a grass-roots problem for long-term TV broadcasters. As Katzenbach et al. (2014) affirm conventional management approaches are primarily programmatic, founded upon pyramid structures to best manage resources, filter risk and uphold homogeneity. Conversely, Saunière (2013, p.6) deems strategic-level creativity as grounded in a very human, rather than a procedural, bias. Arguably, when conventional power dynamics confront the need for human-centric climates then creative personnel can be left vulnerable to transitional politics. For example, research by Florida (2005) identified a natural tendency for the self-clustering of 'creatives' into like-minded nodal groups; concurrently, Matthews (2005) noted the strong tendency for creatives to simply leave an organisation once membership numbers in a creative node fell below a minimum threshold. Taken together, these studies imply that a creative unit (or large parts of it) could collectively exit an organisation when members no longer feel sufficiently engaged or valued, enacting an explicit break between idea genesis and idea realisation sides of the production ecology. Given that the 'person-specific nature of much creative talent means it is sometimes non-substitutable' (McKinlay \& Smith, 2009, p.13) such an exodus could irrecoverably strip a content producer of significant ingenuity resource, reducing its ability to compete.

Trends suggest the phenomena of formation and exit of creative communities from media organisations is already occurring - and not just in Australia. In a recent census of creative industries in the United Kingdom it was reported that up to four in ten of the television workforce choose to operate freelance, either as independents or in loosely networked boutique teams, with little long-term loyalty to major broadcasters (Creative Skillset, 2012). However, while this concept of the self-employed freelancer is increasingly emerging as a dominant work model Starkey et al. (2000) suggest that members in ongoing relationship networks (termed 'latent organisations') only go activist when circumstances reach a point of necessity. Enabling workers to mutually cope with the precariousness and difficult conditions of creative work 
collegial friendships reinforce community coalescence - and a collective exit when circumstances compel. With $40 \%$ of creative practitioners in film, TV and theatre asserting a need for independence, events warrantying divorce of creative groups from former organisations appear ubiquitous. Ursell (2000) even notes an increasing tendency for creative workers to bypass standard employment models and organise their own labour markets. The pastoral housing of creative ecosystems needs much more insight if organisations hope to sustain ideation as an internal capacity.

Referencing back to Australian media market we find support of concepts mentioned above:

- Australian production formally made for, and dependent upon, local circulation is now increasingly globalised;

- Disruptive competition has spurred urgent demand for distinctiveness in television programming. However, institutional approaches to artistic management have increasingly induced creatives to pursue independence from major media producers, instead opting to consider them as external customers of their craft rather than in-house employers.

These two points have helped drive growth of a highly competitive television sector. As mentioned earlier, in the late 1990s Australia had only 5 metropolitan free-to-air channels and a handful of TV production organisations. As of 2018, the nation had 9 public broadcasters, 11 metropolitan commercial networks (with 12 regional affiliate networks), 4 community channels, 7 datacasting channels, over 40 different Australian-based television production companies (both independents and owned subsidiaries of global providers), 17 major entertainment companies spanning various online media, 7 subscription television channels (plus a number of smaller cable and satellite providers operating in limited geographies) servicing a national population of 24 million people. Reevaluating mission priorities Maurice Newman, a recent chairman of the Australian Broadcasting Corporation, went on record saying that a new-look $\mathrm{ABC}$ 'must deliver innovative, entertaining and trustworthy programs and 
services...we must deliver if we are to survive and prosper' (ABC, 2010). This directly linked the $\mathrm{ABC}$ 's future to its ability to originate, as opposed to its earlier focus on cost-containment.

Yet, despite importance of creative output to media production, McKinlay \& Smith (2009, p.11) argue that recent inquiries into artistic outputs are still predominantly management-biased with 'neglect of research into the doing or producing side of creative labour'. Furthermore, writings that $d o$ address the producing side of creative labour often seem to assume an objectivist epistemology: 'there has been a somewhat surprising lack of qualitative studies of working conditions in the cultural industries' (Hesmondhalgh \& Baker, 2011, p.34). Studying examples of program development within a public broadcaster such as the $\mathrm{ABC}-$ an organisation independent of commercial agendas and need for advertising income yet premised on engaging a national audience with its renewed drive to create - seems a reasonable means of progressing such knowledge.

\section{Research methodology}

The Australian Broadcasting Corporation $(\mathrm{ABC})$ is a non-profit organisation commissioned in 1932 as the nation's public broadcaster. Modelled on the British Broadcasting Corporation the $\mathrm{ABC}$ has a long-standing reputation for both conservatism and television quality. More recently, it finds itself engaged in a media sector undergoing rapid disruption: commoditisation, new methods of delivery, aggressive competition and casualisation of labour. Ability to successfully engage an increasingly sophisticated audience is regarded as an essential capacity within this environment.

Interviewing in-situ production teams given responsibility for driving the next generation of creative content our methodology was primarily phenomenological in nature: 
Stage 1 Build a frame of reference for TV media by adapting learning from three previous projects by the authors. These included studies of creativity within small/medium enterprise (SME), high-tech and engineering services (encompassing 180 separate organisations). An extensive literature review of broadcast media was also undertaken to better understand how television production differed from sectors already examined.

Stage 2 Draft frame of reference from Stage 1 was discussed with two movie actors, a director and television executive producer to refine knowledge prior to dialogue with the $\mathrm{ABC}$.

Stage 317 individual interviews of 50-90 minutes with the creative talent and production management behind three recent $\mathrm{ABC}$ television shows:

\begin{tabular}{|l|l|l|}
\hline \multicolumn{1}{|c|}{ Production/Show } & \multicolumn{1}{|c|}{ Interviewee } & \multicolumn{1}{c|}{ Gender/age } \\
\hline \multirow{2}{*}{ Giggle \& Hoot } & Lead actor/host & Male, 20-24 \\
(Daily children's show) & Series writer & Female, 35-39 \\
& Director & Female, 35-39 \\
& Production manager & Female, 40-44 \\
& Series producer & Female, 40-44 \\
& Executive producer & Female, 45-49 \\
\hline \multirow{2}{*}{ Reality Check } & Lead actor/host & Male, 30-34 \\
(Weekly panel discussion and & Concept designer & Male, 50-54 \\
comedy show) & Director/producer & Female, 45-49 \\
& Executive producer & Female, 45-49 \\
\hline \multirow{2}{*}{ The Code } & Production company co-owner & Male, 50-54 \\
(Six-episode political drama mini- & Writer/producer & Male, 30-34 \\
series) & Sead actor & Female, 30-34 \\
& Series producer & Female, 45-49 \\
& Production company co-owner (1) & Male, 45-49 \\
& Production company co-owner (2) & Male, 50-54 \\
\hline
\end{tabular}

Different genres were chosen to better understand common themes across creative television and management approaches to elicit best performance from creatives involved. The authors also attended tapings of Giggle \& Hoot and Reality Check to directly observe operational interplay of cast, crew and audience.

Stage 4 Follow-up dialogue/session with ABC Head of TV entertainment and executive team to better understand wider $\mathrm{ABC}$ priorities, methods and cultural norms enclosing 
production teams from Stage 3. This consisted of individual conversations plus openforum discussion with 18 senior producers/department heads.

Individual dialogues were semi-structured but highly interviewee-driven. Participants could respond in their own words, frame constructs and initiate digressions while reflective questioning allowed emergent themes to be probed. Digital recordings produced 99,000 words of transcript that were then subjected to line-by-line data coding into common motifs and aggregated into thematic categories. Categories were assayed using Nvivo (QSR International, Melbourne) statistical software to derive relative importance of category to enabling a creative outcome, frequency of a category appearing during interviews, connection to other data categories (i.e. prerequisites and post-requisites, etc.), characteristics enabling a category, weighting factors... and so on. Mapping categories allowed an overarching framework to be constructed regarding how creativity/ideation germinated and turned towards novel outcomes.

The research concluded in 2016 with a formal presentation and report of findings to ABC senior management.

\section{Findings and Discussion}

A government-owned broadcaster, $\mathrm{ABC}$ was inevitably structured as a hierarchy making agility and change harder to implement. Meeting the challenge of engaging a younger and more tech savvy demographic, the $\mathrm{ABC}$ chose to insert highly motivated staff into positions where they could quickly inspire new operational outcomes. In turn, production teams accepted such appointments as tacit permission to build islands of semi-independent counter-culture even when these stood against $\mathrm{ABC}$ traditional memes. These two areas - human desire to be creative and a fertile environment to encourage its emergence - can be regarded as separate but highly interconnected aspects of the creative modus.

Personal Creativity 
Concentrating first upon personal creative capacities, these generally fit into four major categories.

Table 1. Weighting of major creativity attributes.

\begin{tabular}{|l|c|c|}
\hline \multicolumn{1}{|c|}{ Creativity Requisites } & $\begin{array}{c}\text { References } \\
\text { (518 total) }\end{array}$ & $\begin{array}{c}\text { Importance } \\
\%\end{array}$ \\
\hline Individual motivation & 333 & 64.3 \\
\cline { 2 - 3 } Imagination & 141 & 27.2 \\
\hline $\begin{array}{l}\text { Personal intent / creative ambition } \\
\text { Learning/knowledge }\end{array}$ & 31 & 6.0 \\
\hline
\end{tabular}

From Table 1 motivation to be creative was of acute importance. While rewards played a part in encouraging this, intrinsic incentives (pride in achievement) far outweighed the extrinsic (money), particularly in Giggle and Hoot and The Code. As the chief writer on Giggle and Hoot mentioned 'it's all about doing something you love'. The relative weightings of the four main attributes also suggests that even a moderate boost in individual motivation can yield substantial increase in the power to generate ideas. The director/producer of Reality Check referenced her determination to get that show made as 'if you believe in something, you'd die in a ditch for it' so clearly there is a strong emotional element to creative development.

Depth of personal imaginative challenge also rated highly: 'to keep up with the world we are always thinking of new things' (writer, Giggle and Hoot). However, imagination was also most often linked to focused intent with the former seen as given direction by the latter. For example, one of the co-owners of Playmaker (production house behind The Code) observed of the miniseries chief writer that her "commitment to the project was unwavering for three years and that's a long time to be excited about something'. In support, the series producer repeatedly stated of cast and crew that 'the passion on The Code was so high that everyone wanted to get it right'. These suggest a singularity of purpose sufficient to inspire a creative vision and the collective drive to have that vision appreciated by an audience.

Surprisingly, individual knowledge didn't achieve major standing compared to the three other key requisites - but viewing this as a stand-alone statistic is also a little misleading. There was 
a distinct flavor in the data that creative people do regard knowledge as important, however group learnings appear more esteemed than those owned by any one person. Informal storytelling and internal social network exchanges help harmonise a common sense of purpose turning tacit expertise into more explicit value and authenticating information resources communally held. The director for Reality Check spoke of 'that sense of something happening in the room' that flowed from collaboration and knowledge cross-pollination. While personal expertise is respected, an artistic performance is perceived more as an ensemble outcome of network engagement than simple reflexive execution of individual know-how.

\section{Creative Ecology}

The research also underscored the critical nature of sustaining an ecosystem in which creatives can thrive. The productions examined presented as close-knit functional communities with collective social identities. The Giggle and Hoot series producer summed this most important aspect of running her production saying 'there is a real strong sense of what we are', emphasising both the strength of the team bond to one another and her perceived role as existing inside that kinship rather than standing above it.

Ecologies enfolding the television production teams were found to not just be socially-derived but emphatically socially-derived. 683 instances in the transcripts made direct reference to having an empowering team ethos as being fundamental to creative ideation.

Table 2. Weighting of cultural attributes aligned to ideation.

\begin{tabular}{|l|c|c|}
\hline \multicolumn{1}{|c|}{ Ecology Requisites } & $\begin{array}{c}\text { References } \\
(683 \text { total) }\end{array}$ & $\begin{array}{c}\text { Importance } \\
\%\end{array}$ \\
\hline Communication etiquettes & 167 & 24.5 \\
\cline { 2 - 3 } Teaming and team compatibility & 148 & 21.7 \\
\cline { 2 - 3 } Idea socialisation & 121 & 17.7 \\
Mutual respect & 90 & 13.2 \\
Autonomy & 89 & 13.0 \\
Ability to experiment and improvise & 68 & 10.0 \\
\hline
\end{tabular}


Aspects of this human-centric dynamic can be seen in the layout of Table 2. Respondents highly valued the use of informal etiquettes to help mediate internal communication, uphold values, support problem solving, promote humour and so on. Szulanski (1996) terms such unspoken understandings 'sticky' knowledge - a community framework of social, collaborative and decision-making accords around which praxis operates. These organic behaviours were most notable during the observed tapings of Giggle and Hoot and Reality Check where teams for both productions seemed to enjoy themselves as much as the studio audience. Freely trading jokes, banter and the occasional tongue-in-cheek impertinence for isolated mistakes these undertakings exhibited many of the attributes of improv(ision) comedy - yet production members seemed to know where the lines of social acceptance were tacitly drawn and stayed within these unwritten guidelines. A professional, and for those present highly entertaining, outcome was the result.

Outside of the camera view, all three production teams adopted energetic attitudes towards fully exploiting local resources and field testing ways of doing things while attempting to 'stay under the radar' of bureaucratic scrutiny. Internal cohesion and interaction (ideas collectively brainstormed in ever-widening circles; contrasting viewpoints examined for value; solutions jointly cultivated) got things done. Likely concepts became limited experiments where risking small-scale failure to prove a novel benefit was entirely acceptable. Promoting a small number of keystone behaviours (habits with power to change other habits) within visibly supported archetype teams the ABC had apparently - and independently - instigated Duhigg's (2014) approach to cultural change.

This autonomy and experimentation was particularly well-developed within the Giggle and Hoot team who seemed to take particular pride in both their collegiality and penchant for creative rule-bending. Giggle and Hoot also seemed to buck the media trend towards using freelancers, instead having an exceedingly loyal team who attracted additional talent mostly by 
positive word of mouth. Their production's capacity to successfully inspire and attract creative curiosity led their series producer to comment 'there's a freedom between the writers and producers turning ideas around', while the Head of ABC Entertainment reflected of their team approach that 'the creativity of the stuff you make will draw other creative people to you'.

The inclination to creative improvising was also mimicked to a lesser extent by The Code which had to work within a fixed budget but also had a production team that ardently believed in bringing their script to life however they could. This resulted in some rather innovative dronemounted camera work and hasty scene filming around (and within) Australia's Parliament House. Alternatively, Reality Check was more stage-managed - with timeslot and format boundaries some entertaining extemporisations were edited post-production and never made it to air.

A creative ecology needs a compelling leader for pastoral upkeep of the system and the establishing of a cultural meme of 'what really matters to us'. A filter for decisions (as opposed to absolute control of decision-making) and screen for assumptions (i.e. issues, ideas, investments, etc.) they foster outcomes and build a covenant-style orientation between the business and its people. A trusted leader was regarded by interviewees as essential - a distinctive performance was held as unlikely if the wrong personality is put in charge.

Table 3. Weighting of leadership attributes.

\begin{tabular}{|l|c:c|}
\hline \multicolumn{1}{|c|}{ Leadership Requisites } & $\begin{array}{c}\text { References } \\
\text { (339 total) }\end{array}$ & $\begin{array}{c}\text { Importance } \\
\%\end{array}$ \\
\hline Team building & 89 & 22.3 \\
\cline { 2 - 3 } Supportive & 80 & 20.1 \\
Clarity of direction & 53 & 13.3 \\
Ability to sponsor/advocate ideas & 49 & 12.3 \\
Relationship networking & 45 & 11.3 \\
Commercial awareness & 36 & 9.0 \\
Risk taker & 26 & 6.5 \\
\hline Other & 21 & 5.3 \\
\hline
\end{tabular}

This view of leaders as mediators is at odds with many of the control norms of traditional hierarchy but very supportive of authors like Townley et al. (2009) who assert that creative 
industries require a different form of management. Pivotal as go-between for teams with the wider $\mathrm{ABC}$ organisation, the role was perceived more as productions' outward face than hierarchic director. Ambassador to other departments, sponsor of ideas, protector of the creative unit when it came under pressure from external forces and employer of unique metaskills to expedite the team as a whole, they were particularly practiced in three key areas:

- Alignment. Facilitate commitment and buy-in from teams to the envisioned future. Forging this link requires leaders to understand both enterprise objectives and personal ambitions of staff, to 'create a situation they've got to want to get into...and to actually flourish once they're there' (Head of ABC TV Entertainment);

- Advocacy. Working to uncover new thoughts; translating into readily grasped language; selling; orchestrating concept refinement... the ability to 'pitch' was regarded as something of an art form. Creative teams looked to their managers to help attune concepts to business need and passionately promote 'taking risks..., fostering new talent. Trying out new ideas and actual originality, doing something you haven't done before' (Executive Producer, Reality Check);

- Affirmation. As intrinsic reward far outweighed extrinsic, accolades from management validated creative effort and directly fed team motivation to do even more next time. As one senior manager stated 'you've got to acknowledge people's ideas' (production company co-owner, Reality Check).

The above were a mix of tacit and procedural. Related activity also encouraged building layers of advantage and a future resource base in line with $\mathrm{ABC}$ strategy (e.g. distribution channels, finance, expertise, technology, repute, merchandising, social capital) plus partner relationships for resources the $\mathrm{ABC}$ didn't wish to directly develop themselves. This latter item production teams opportunistically leveraged as non-core (i.e. non-socially disruptive) augments to their own work and production community. 


\section{Conclusion}

The $\mathrm{ABC}$ was extremely forthcoming in access to their management and creative talent. The decision to embed independent team cultures within their traditional framework was also an intriguing decision. Certainly, the productions examined possessed distinctive worldviews of which they were very protective - teams worked out their own unique way of doing things, repeatedly stepping outside the standing bureaucracy (when they could get away with it) to follow heuristics they thought could better guide a desired result. Yet these behaviours were also tolerated within the wider workplace culture. As one senior ABC creative director characterised all three shows under examination: 'know the rules before you break them'. Such latitude for rule-breakers improvising was regarded as worthwhile if a genuinely creative performance emerged as a result.

Even so, not all shows survive. Of productions examined for this research, children's entertainment show Giggle \& Hoot goes from strength to strength attracting praise for innovative format and wide audience appeal. It is now in its ninth season (as of 2018), has won numerous television and entertainment awards for original music and design and become synonymous with children's television in Australia. The political mini-series The Code was very successful, earning acclaim for creating a new genre of thriller with a high technical content. It also used novel camera work, filming techniques and achieved high viewer ratings. The Code was distributed internationally (airing in the UK, US and Canada) with a sequel series later commissioned. Both Giggle and Hoot and The Code productions had very strong internal memes with motivated people who took pride in contributing to something greater than themselves. Conversely, Reality Check, initially regarded as an innovative experiment in topic choice and presentation format, exhibited less success and was unable to campaign for a more extended term.

At the beginning of this paper we noted two concepts for exploration: 
1. Attributes fostering creativity in broadcast programming;

2. Ecological approaches required to promote program distinctiveness.

Observing the teams in action it was clear they exist as high-energy and highly motivated ecosystems. To sustain that energy, humour was often used as bond and social lubricant. Teasing to inspire imaginative responses from others; informal accolades awarded by peers to incent responses; a general sense of fun - these 'clans' enjoyed working together as creative communities rather than organisational units. This was most evident for Giggle \& Hoot which had the longest life-span at nine seasons, compared to Reality Check and The Code which were limited to twelve episodes each (the latter being six per series). The challenge of stable clans versus short-term teams and links to successful creativity is an interesting area for future study.

At the organisational level realising innovative potential benefits from having workable practices and support for local leadership. Long risk management procedures incur opportunity cost. For example, The Code took approximately four years to progress from initial concept to first series airing, requiring multiple procedural steps with several stage-gate approvals compounding timeframes. During that interval, the executive producers exhibited impressive leadership to keep key members of the production team included and committed. Steering from within not above, taking active part in the community dynamic and ownership of team advocacy role, leaders orchestrate connections between personal and organisational objectives to keep the production team centred, motivated and enterprise-attuned. This requires careful selection of a compatible principal to bring forth the best from a team, ensuring both sides see worth in an ongoing creative relationship. Contractual partnering and selective engagement of free-lance talent can then be sourced to help fill gaps - and external partnering models for cocreation in TV broadcasting is also an area worthy of additional investigation.

The ability to accomplish something extraordinary in television was best summed by the main writer and creative talent behind The Code reflecting upon her feelings in helping build a show 
earning accolades for the ABC: 'I sit in the darkened audience and listen to people enjoying it - and that's incredibly gratifying'.

\section{References}

ABC (2010). Strategic Plan 2010-13: A Clear Direction for the ABC, ABC Head Office, Sydney.

Carter, S. \& West, M. (1998). Reflexivity, effectiveness and mental health in BBC-TV production teams, Small Group Research 29(5), 583-601.

Creative Skillset (2012). Employment Census of the Creative Media Industries, Creative Skillset, London.

Doyle, G. (2010). From television to multi-platform: Less from more of more from less?, Convergence: The International Journal of Research into New Media Technologies 16(4), 431-449.

Doyle, G \& Paterson, R. (2008). Public Policy and Independent Television Production In the U.K., Journal of Media Business Studies 5(3), 17-33.

Duhigg, C. (2014) The Power of Habit: Why We Do What We Do in Life and Business, Random House, New York.

Dunne, A. (2007). The ABC's Digital Transformation: A Continuing Story, Australian Media Traditions Conference, 22-23 November, Charles Sturt University, Bathurst Australia.

Florida, R. (2005). Creativity special: where it's at, New Scientist 2523, 29 October.

Gottlieb, J. \& Willmott, P. (2014). The Digital Tipping Point: McKinsey Global Survey Results, McKinsey\&Co., accessed 15 January 2018. http://www.mckinsey.com/business-functions/business-technology/our-insights/thedigital-tipping-point-mckinsey-global-survey-results

Hesmondhalgh, D. \& Baker, S. (2008). Creative work and emotional labour in the television industry, Theory, Culture and Society 25(7-8), 97-118.

Hesmondhalgh, D. \& Baker, S. (2011). A very complicated version of freedom: conditions and experiences of creative labour in three cultural industries', Variant: Cross Currents in Culture 41(Spring), 34-38.

Katzenbach, J., von Post, R. \& Thomas, J. (2014). The critical few: components of a truly effective culture, Strategy+Business, Spring (74), 1-9.

Kean, M. \& Moran, A. (2008). Television's new engines, Television \& New Media 9(2), 155-169.

McKinlay, A. \& Smith, C. (2009). Creative Labour: Working in Creative Industries, Palgrave Macmillan, UK. 
Magder, T. (2004). The end of TV 101: reality programs, formats and the new business of televsion, in Reality TV: Remaking Television Culture, ed. Murray, S. and Ouellette, L., 137-156, NYU Press, New York.

Matthews, R. (2005). Should I stay or should I go?, New Scientist 188 (2531/2532) December, 30-31.

O'Regan, T. \& Potter, A. (2013). Globalisation from within? The de-nationalising of Australian film and television production, Media International Australia, 149, 5-14.

Saunière, J-C, (2013). Innovation that counts, World Watch, No. 2, PriceWaterhouseCoopers, 6-7.

Starkey, K. Barnatt, C. \& Tempest, S. (2000). Beyond networks and hierarchies: latent orgnisations in the U.K. television industry, Organization Science 11(3), 299-305.

Szulanski, G. (1996). Exploring internal stickiness: impediments to the transfer of best practice within the firm, Strategic Management Journal 17(2), 27-43.

Townley, B. Beech, N. \& McKinlay, A. (2009). Managing in the creative industries: managing the motley crew, Human Relations 62(7), 937-962.

Ursell, G., (2000). Television production: issues of exploitation, commodification and subjectivity in UK television labour markets, Media, Culture \& Society 22, 805-825. 